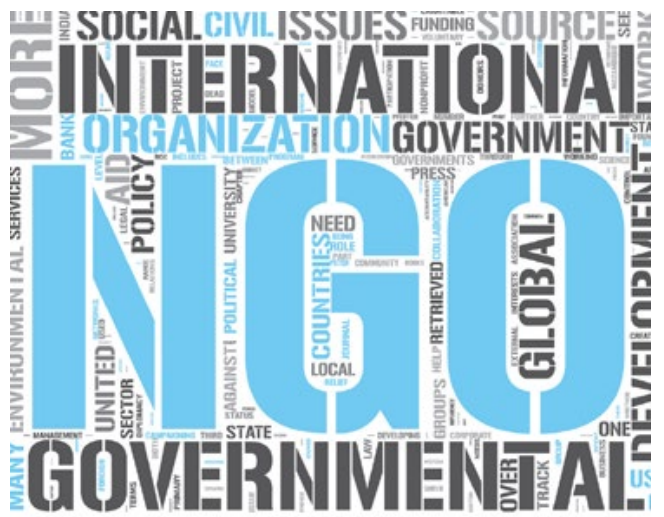

\section{Conceptual Confusion in the Research on Chinese Civil Society}

\section{Taru Salmenkari}

Chinese civil society research is obsessed with finding non-governmental organisations. In this search, different types of civil society organisations are conflated, and nongovernmentality becomes the sole factor that matters. Analytical accuracy is lost when too many things are fused under one term, especially when more accurate and nuanced terminology is available.
Research on Chinese civil society is consumed with the obsession of finding non-governmental organisations (NGOs). In this search, non-governmentality becomes the sole factor that matters in civil society. As a consequence, all civil society organisations and functions have been lumped together, perhaps with the expectation that any organisation that is non-governmental will be conducive to facilitating all the positives associated with civil society. This is evidence of conceptual confusion. Analytical accuracy is lost when too many things are fused under one term, especially when more accurate and nuanced terminology is available. In China studies, this conceptual bloating concerns both civil society organisations and civil society itself.

\section{Making Sense of the Diversity in Chinese Civil Society}

The field of China studies often conflates different types of civil society organisations. For instance, the term 'NGO' is used to refer to a wide range of organisations, regardless of whether they are political or not. Elsewhere, NGO is usually reserved for associations engaged in advocacy or participating in developmental projects. In particular, in the West NGOs constitute a self-proclaimed category used for advocacy and for demanding inclusion in policy-making processes. The category is not politically neutral, but mostly comes with a liberal or leftist worldview. Some other organisations, such as 'think tanks', often hold more rightist stances but may occasionally engage in activities similar to what NGOs do. In Japanese parlance, the term NGO is used to refer to those organisations engaged in developmental aid, 
while those that work on domestic arenas are usually called non-profit organisations (NPOs).

Instead of NGO, a number of other terms are available for voluntary organisations engaging in societal service production and its private funding. Others include NPOs, philanthropic organisations, charities, aid organisations, foundations, cooperatives, social enterprises, and selfhelp groups. 'NPO', in particular, is a legal category employed in relation to specific tax regulations reserved for voluntary associations. The official Chinese category'citizen-initiated non-enterprise units' (minban feiqiye danwei)-conveys the same meaning. Because many civil society organisations are actually registered within this category, Chinese scholars, correctly, use 'NPO' at least as often as 'NGO'. In addition to NGOs and NPOs, civil societies are populated by other types of organisations such as interest groups, professional associations, sports clubs, support groups, academic societies, syndicates, cooperatives, and many others.

Furthermore, civil society includes more fluid and less organised forms of associating. Civil societies contain social movements, campaign networks, community assemblies, voluntary projects, and temporary gatherings and forums inspired by public issues. These less formal platforms and networks are even closer to civil society ideals than formal associations are. Besides, the fall of communism in Eastern Europe and the Arab Spring demonstrated that these non-organised or loosely organised forms of public activity have more potential than registered associations for mobilising social pressure for democratisation.

\section{Conceptual Mistakes}

China studies would benefit from using more specific terms for different types of organisations because different organisations do dissimilar things and fulfil particular attributes of civil society in distinct ways. The use of the term 'NGO' for many analytically diverse types of organisations in society suggests that NGOs can do it all just by the virtue of their nongovernmentality.

'NGOs' are expected to defend interests, channel developmental aid, give voice to society, produce social services for the needy, protect rights, empower the marginalised, self-regulate industries, offer opportunities for popular participation, advocate liberal causes, and, eventually, demand a democratic political system. This list should make it evident that an individual NGO can hardly do everything and that some kind of division of labour is needed to fulfil these promises of civil society. This division of labour should be recognised and highlighted conceptually.

Conflating too many aspects together blurs analytical clarity and results in misinterpretations. Because terminology makes no distinctions between causes and roles in civil society, conclusions based on one specific type of civil society organisation have been expanded to cover them all. Conceptual confusion has contributed to consensus that Chinese NGOs are mainly service providers. Had service-providing organisations been classified as NPOs, attention could have been focused on political NGO activities as such. In fact, China is no exception. Nowhere in the world do advocacy NGOs make up the majority of civil society organisations.

Currently, analytical approaches that suit one type of civil society organisation are expected to suit them all. It makes complete sense to analyse as an epistemic community a global advocacy network that produces and spreads new knowledge and vocabulary in order to make violence against women a political issue. Chinese feminist NGOs campaigning against domestic violence are part of this epistemic community (Milwertz 
and $\mathrm{Bu}$ 2007). However, non-profit service providers hardly form such an epistemic community (Hsu and Hasmath 2017).

Orally, I have heard my colleagues suggest even wilder ideas, such as using the One Foundation, a private philanthropic foundation, to discuss NGO advocacy, while still opining that there is no connection between charity and civil society. Using the term 'NGO' for all privately established associations makes it non-transparent when they are philanthropic and when they engage in more political activities, such as policy advocacy and interest promotion.

This type of conceptual confusion has caused a major theoretical confusion in China studies. Only China studies uses the theory of corporatism about interest groups for analysing NGOs, as if all associations automatically equal intermediary organisations and interest groups (Zhang 2015). Those who introduced the term 'corporatism' to Chinese studies used it correctly to analyse labour union activities and business associations (Lee 1991). Corporatism is a form of interest representation delegating regulatory functions to interest groups in civil society. Hence, it has been described as a mixed mode of policy-making, private interest government, and self-regulation (Streeck and Schmitter 1985).

However, NGOs are not the kinds of organisations that could participate in corporatism. They do not represent any sector and cannot make agreements on behalf of a sector. Many NGOs have only a few members. Thus, they are not intermediary organisations able to talk to the state or other interest groups in the name of a coherent social group. Furthermore, corporatism does not contain a comprehensive vision about the regulation of civil society as a whole. Corporatist compacts regulate only the relevant parties, such as relations between the labour and the employers, usually under the auspices of the state. Apart from these interest groups, all corporatist countries have voluntary associations not connected to this system.

\section{Macro Consequences}

Different types of organisations fulfil the promise of civil society in different ways. NPOs by definition emphasise voluntariness; advocacy NGOs monitor the government and demand a more inclusive political system; the philanthropic sector solicits non-state resources for causes determined as being important by society; interest groups engage in social mediation of interests. All of these attributes and functions are characteristics or forms of self-organising in society.

Using different terms for various organisations in civil society, and even for diverse visions of civil society, is advisable because these differentiated terms imply different relations to the state. Liberals see that advocacy NGOs offer policy alternatives in the public sphere. In more leftist interpretations, NGOs and social movements epitomise anti-hegemonic organising to demand inclusion and voice for the marginalised. Special-interest groups, which derive from the theory of pluralism rather than of civil society, lobby the government. In corporatism, certain intermediary groups participate in social mediation of interests in civil society, nowadays often through tripartite arrangements involving the state. Non-profit service production is present in most societies, but is theoretically emphasised in the neoliberal strategy for the state to reduce its social service burden by outsourcing services to civil society. Communitarianism wants to reclaim faceto-face social life and cultivate social capital in everyday life. For acquiring social capital, any form of association that brings people together is fine, recreational associations and self-help groups included. In the communitarian vision, associational life is a school for citizenship and political 
participation. Theoretically speaking, none of these relationships equal categorical separation from the state.

Civil society itself is a vast container of associative activities and 'occasional' and 'episodic publics', which together constitute public life (Habermas 1996). As a whole, it seldom promotes any particular political opinion, supports any particular form of activity, or holds any united stance in regards to the government. In civil society, hegemonic groups associate alongside with anti-hegemonic forces.

Due to different contributions to civil society by different types of associations, just to show that civil society is there tells us little about what is happening within civil society or the political consequences of what is occurring. The developments are neither linear nor similar to associations of all types. For example, after the crushing of the massive protests in Beijing in 1989, the first independent aid organisations rocketed to fame, according to their own understanding because the state media needed positive news in gloomy times. Developments in different fields and between different types of civil society organisations can be contradictory. For example, some Chinese advocacy NGOs I have interviewed find that the opportunities emerging with the growth of the third sector contradict activists' own ideals about NGO work.

\section{Using Correct Terminology}

Conceptual confusion in naming organisations leads to a poor understanding of civil society itself. The use of more accurate terms is not only beneficial for semantic clarity, but makes visible the unevenness of forces and growth trends within civil society.
Hence, it may be advisable to use more confined terms which focus on some aspects of civil society only. 'Associational society' suffices if the purpose is to research formal associational activity without complex networks and causes that make these associations, ideally, contribute to nationallevel publics and to a community of citizens. Other terms used far too little in China studies are 'third sector', or its equivalents, 'non-profit sector' and 'voluntary sector'. This omission is particularly surprising considering the fast development of this sector in China. Not only would analytical nuance be gained if third sector service production was distinguished from political aspects of civil society, but using these terms would treat China more equally than current civil society research does. Although Chinese associations are not always fully 'autonomous' (whatever that means), the existence of three separate sectors is evident. China observably has a public sector, a private sector, and a third sector.

Conceptual clarity is needed to understand what happens in Chinese civil society. Consequences are hardly the same if the number of political advocacy groups or the number of third sector service providers grows. These types of organisations answer to very different social needs, have different relations to the government, and contribute differently to politics and democratisation. One part of civil society can be growing even if others are not or even if its growth happens at the expense of another part.

For gaining a more comprehensive, nuanced and meaningful understanding about Chinese civil society, researchers should do what social sciences have always taught them to do: use accurate and exact terminology to specify what is being referred to and what is expected of the research objects. 
This text is taken from Gilded Age: A Year of Chinese Labour, Civil Society, and Rights, Made in China Yearbook 2017, edited by Ivan Franceschini and Nicholas Loubere, published 2018 by ANU Press, The Australian National University, Canberra, Australia.

doi.org/10.22459/MIC.04.2018.18 